\title{
The Interpretation of Cause of Death Among Infants
}

\author{
Magdalena Bengtsson
}

\section{Introduction}

I $\mathrm{n}$ this paper I will discuss the interpretation of cause of death in Swedish historical source material. A short introduction to the organisations and regulations concerning cause of death information in Sweden is followed by an examination of how previous Swedish researchers have interpreted and used this kind of information. Thereafter, cause of death patterns in infancy are analyzed for two birth cohorts in nineteenth century Linköping. My aim is also to discuss the interpretation of separate causes of death as well as the changes in mortality patterns in relation to the modification of regulations and praxis.

In 1738, the consistories were ordered by Sundhetskommissionen (the Health Commission) to report the number of births and deaths that occurred in the parishes and to give detailed information on contagious diseases. At this time information on cause of death was not reported. It was not until eight years later, in 1746, that the ambition to collect information on causes of mortality became apparent. That year the secretary of Vetenskapsakademien (the Academy of Science), Pehr Elvius, and the politician I. A. von Lantingshausen both presented reports addressed to a parliamentary committee with suggestions on how to improve population statistics. Elvius wanted to establish the size of the population and therefore stressed the need for national statistics, while von Lantingshausen demanded that the collection of data should be performed in the same way all over the country using special forms. Von Lantingshausen also argued that it was necessary to collect information on diseases with high mortality in order to keep the death rate down, especially among children. These reports led to intensive discussion on the need for further statistics, as well as on the clergy's competence in medical matters. This discussion 
resulted in a proposal in 1748 for a national statistics department, and the following year Tabellverket (Swedish Population Statistics) was established. ${ }^{1}$

It was stipulated that the clergy should fill in three tables every year and send them to Tabellverket. Table I contained the number of baptized, married and buried in the parish each month, and there were separate columns for men and women. Table II comprised the distribution of deaths in separate age groups and according to sex and cause of death, while Table III included information on population according to separate age groups, sex and social class.

Table II was revised four times between 1749 and 1830, after which the clergy was no longer required to send in cause of death information for all deaths. ${ }^{2}$ The first version, used from 1749 to 1773 , contained 33 cause of death categories. ${ }^{3}$ As the historian of ideas Eva Nyström has pointed out, this first Swedish list of causes of death was not complete. Her opinion is that it is likely that physicians and ordinary people had a more extensive "classification." Some of the categories contained more than one diagnosis, and not all causes listed in one category were related to one other. Smallpox and measles were placed together in one category, as were chest disease and consumption. Many of the categories contained descriptions of symptoms such as fevers, pains in the chest, grippe and colic. ${ }^{5}$ For an observer of today, it is difficult to find any logical consistency in the classification.

The second version was introduced in 1774 and was valid until 1802. The number of causes had increased to 41 and one of the new causes was unspecified disease, a category that previously had been missing. Other changes included the separation

1 Concerning the establishment and early history of vital statistics in Sweden, see O. E. A. Hjelt, "Det svenska tabellverkets uppkomst, organisation och tidigare verksamhet. Några minnesblad ur den svensk-finska befolkningsstatistikens historia," Fennia, 16 (1900), E. Arosenius, Bidrag till det svenska Tabellverkets historia (Stockholm, 1928), O. E. A. Hjelt, Svenska och finska medicinalverkets historia 1663-1812 (Helsingfors, 1891-1892).

2 Only deaths in certain categories were to be reported, such as suicide, murder, childbirth and epidemic diseases. Arosenius (1928), 65.

3 Gustaf Sundbärg "Dödligheten av lungtuberkulos i Sverige åren 1751/1830," Statistisk Tidskrift (1905), 196-197.

4 Eva Nyström "Den svenska dödsorsaksstatistikens framväxt och tidiga historia," in Hälsa, sjukdom, dödsorsak. Studier i begreppens teori och historia, ed. L. Nordenfelt (Linköping, 1986), 120.

5 Nyström (1986), 118-120. 
of smallpox and measles, and the assignment of consumption to its own category. ${ }^{6}$ Table II was further revised in 1802, 1811 and 1821 . $^{7}$

In 1831 Tabellkommissionen (the Swedish Population Commission) decided that the clergy would no longer be required to report death statistics unless the deaths were caused by miscarriage or delivery, by specific accidents or by smallpox. Deaths caused by infectious diseases such as measles, scarlet fever and dysentery were to be reported if there were extensive epidemics. As a result of this decision, Swedish cause of death statistics are incomplete for the period 1831 to 1860, and causes of death were not always reported in the death and burial records. ${ }^{8}$

Information on cause of death underwent further change in 1860, when death certificates issued by physicians were required for all deaths occurring in the cities and towns. In the case of women in confinement and newborns, a certificate issued by a certified midwife was sufficient. Death certificates were required in the countryside only if the deceased had been treated by a doctor for the final illness. ${ }^{9}$ The reason death certificates were not required for all deaths in Sweden was the lack of physicians in sparsely populated areas. In the same year, Svenska Läkaresällskapet (the Swedish Medical Society) compiled a bilingual nomenclature for reporting on causes of death. The list consisted of 115 recommended cause of death categories in Swedish and Latin. Läkaresällskapet wished to facilitate the reporting and hoped to attain uniform denominations. ${ }^{10}$

\section{Previous Research}

Several Swedish studies aimed at understanding and explaining changes in mortality during the eighteenth and nineteenth centuries have discussed the validity of cause of death information. ${ }^{11}$ Important methodological questions have been raised con-

6 Nyström (1986), 120, 126-130.

7 B. Ingemar B. Lindahl, "Dödsorsaksstatistikens problem i modern tid," in Hälsa, sjukdom, dödsorsak. Studier i begreppens teori och historia, ed. L. Nordenfelt (Linköping, 1986), 151153.

8 Lindahl (1986), 136.

9 Svensk Författningssamling (SFS) 1859:64.

10 SFS 1860:13; Fr. Tholander, C. G. Grähs and K. F. Levin, "Den 26 April. Constitutio epidemica. Betänkande om mortalitetsstatistiken," Förhandlingar vid Svenska Läkare-sällskapets sammankomster frain och med Okt. 1858 till och med Sept.1859 (Stockholm, 1859), 136-153.

11 Arthur Imhof and Bengt I. Lindskog, "Dödsorsakerna i Sydsverige 1749-1773," Sydsvenska medicinhistoriska sällskapets årsskrift, (1973), 120-143; Lars Widén "Mortality and causes of death in Sweden during the 18th century," Statistisk Tidskrift, 13:2 (1975), 93-104; 
cerning the determination of cause of death as well as the researcher's interpretation of them. The fact that the parish priests in Sweden were long responsible for the identification and reporting of causes of death has given rise to a discussion of the medical competence of the clergy. Did they have the capacity and ability to determine cause of death correctly? Other issues in this debate concern the level of accomplishment in medical science in the eighteenth and nineteenth centuries and the effects of instructions and regulations on cause of death registration. Variation in registration and mortality levels due to the practices of individual ministers have also been discussed.

In an early study on causes of death in southern Sweden 1749-1773, Arthur Imhof and Bengt Lindskog raised the question of the clergy's medical competence. They argued that one cannot assume that the medical standard of the clergy was good just because several medical volumes were published in Swedish in the eighteenth century and were widely spread throughout the country, or because the clergy was taught some rudiments of medicine. Even contemporaries did not think too highly of the medical education for the clergy. The scientists of repute at the time, Carl von Linné and Abraham Bäck, had many times proposed reforms of the clergy's medical education in order to improve reporting of mortality statistics. Furthermore, Imhof and Lindskog point out that, although the role of medical literature and education should be played down, the clergy did have some practical medical experience. They often acted as local doctors, as only about two dozen district medical officers were on duty in Sweden-Finland at the end of the eighteenth century. The clergy's ability to make a fairly correct diagnosis according to the prevailing medical theories should therefore not be underestimated, in Imhof s and Lindskog's view. ${ }^{12}$

The historian Britt-Inger Puranen has emphasized the clergy's central role for diagnosis and medical therapy. Puranen, who thoroughly discussed the validity of cause of death information in her study of tuberculosis in Sweden 1750-1980, expressed the opinion that their theoretical knowledge of medicine was limited and of uneven quality, a condition that characterized medical science in general. "The value of the medical education that the clergy received at gymnasium and university

Britt-Inger Puranen, Tuberkulos. En sjukdoms förekomst och dess orsaker, Sverige 1750-1980 (Umeå, 1984), Nyström (1986), 107-133; Tommy Bengtsson, "Mortality and causes of death in Västanfors parish, Sweden, 1700-1925," in Society, Health and Population during the Demographic Transition, eds. A. Brändström and L-G. Tedebrand (Stockholm, 1988), 461-493; Jan Sundin, "Child mortality and causes of death in a Swedish city, 1750-1860," Historical Methods, 29:3 (1996), 93-106; John Rogers, "Reporting Causes of Death in Sweden, 1750-1950," Journal of the History of Medicine, 54:2 (1999), 190-209.

12 Imhof and Lindskog (1973), 140-141. 
should not be thought of too highly, not even when the students attended seminars by Carl von Linné, [the pediatrician] Nils Rosén von Rosenstein or other as highly qualified scientists." ${ }^{13}$ What Puranen stressed, as did Imhof and Lindskog, is the clergy's valuable practical experience of medicine. She argued that the clergy's responsibility for peoples' health had old roots. In medieval society, diseases were considered as caused by a sinful life, and it was thence the clergy's caring duties were derived. After the Reformation the parish members continued to turn to the parish priest for medical advice and treatment. He was also often the only educated person in the parish and knew the villagers well. ${ }^{14}$ This was a condition that the authorities wanted to make use of when the clergy became responsible for the collection of population statistics, and therefore medical literature specifically addressed to the clergy and other church authorities became available. ${ }^{15}$

Yet another researcher stressing the clergy's practical experience of medicine is Eva Nyström, historian of ideas. In an article on the development of Swedish cause of death statistics she has argued that this practical experience of medicine made the clergy aware of the nature of various diseases and their change over time. They could thereby identify most lethal diseases and recognize significant symptoms, which would have made it easier to make a correct diagnosis. ${ }^{16}$ The significance of taking the disease panorama into account when discussing validity of cause of death information has also been advanced by Lars Widén. In an early article on cause of death specific mortality in late eighteenth century Sweden, he stated that, "even if it is true that the clergy was not formally competent for this work, it must have been possible for them to give the appropriate cause in many cases." ${ }^{17}$ He sums up his line of argument with the conclusion that "the clergy was able to state the appropriate cause in the majority of deaths from infectious diseases which have a specific pathological picture." ${ }^{18}$ Jan Sundin, who studied child mortality and causes of death

13 Puranen (1984), 71.

14 Puranen (1984), 54. See also Widén (1975) 94-95; Nyström (1986), 122.

15 Puranen (1984), 59-62.

16 Nyström (1986), 122. It is important to notice that the most lethal diseases in the 18th and 19th centuries were infectious diseases and many of them were relatively easy to identify. They had a characteristic course and some of them also appeared in epidemics. According to Imhof and Lindskog, plague, colic (mage- och bukref), feverish conditions and malaria would have been relatively easy for the clergy to diagnose. Imhof and Lindskog (1973), 141. See also Anders Brändström, "De kärlekslösa mödrarna." Spädbarnsdödligheten med särskild hänsyn till Nedertorneå (Umeå, 1984), 96; Bodil Persson, Pestens gåta. Farsoter i det tidiga 1700-talets Skåne (Lund, 2001), 155-158.

17 Widén (1975), 94.

18 Widén (1975), 94-95. 
in Linköping 1750-1860, has voiced a similar opinion: "we cannot always be certain that the diagnoses were correct, but we can get a crude picture of the symptoms." ${ }^{19}$

Instructions and regulations were other prerequisites for the clergymen's ability to fulfil their duty as registrars of mortality records. One interesting matter is the construction of cause of death categories by Tabellverket. As Jan Sundin has described them, some of the categories were "a mixture of names of specific diseases that are still used, groups of terms that by modern medical standards include rather related diseases, vague symptoms, and totally incomprehensible categories." ${ }^{20} \mathrm{He}$ argued further that "the vicars could probably have recognized certain common diseases such as smallpox and whooping cough relatively easy, whereas other symptoms - diarrhea and other gastrointestinal troubles, for example - might not always have been registered under the same category." ${ }^{21}$ Britt-Inger Puranen actually studied the occurrence of tuberculosis in different categories of causes of death. She could convincingly show that tuberculosis could be hidden in such categories as chest disease, chest fever, chest pain, etc. ${ }^{22}$ To make a correct diagnosis and then place it under the appropriate cause of death category in the mortality table seems to have been difficult enough. Changes in the regulations are likely to cause methodological problems for the researcher, just as they did for cause of death registration. ${ }^{23}$

Britt-Inger Puranen and Tommy Bengtsson have both studied how the registration of causes of death on a parish level was affected by these changes. Puranen concluded that the nomenclature from Tabellverket to some degree influenced the terms in the death and burial register in the period 1750-1830, even though medical books had a stronger influence. ${ }^{24}$ Bengtsson on the other hand, claims that the changes of nomenclature in $1774,1802,1811$, and 1821 seemed not to have "any effect on what the priests in Västanfors registered in the parish registers. Thus, the problem with changes in the nomenclature when constructing continuous time series based on the population statistics does not exist when analysing the parish registers." 25 example from Linköping contradicts Bengtsson's view. When the category "unknown childhood disease" in the first version of Table II was deleted in

19 Sundin (1996), 93.

20 Sundin (1996), 93. See also Imhof and Lindskog (1973), 140.

21 Sundin (1996), 94-95.

22 Puranen (1984), 65.

23 The instructions and regulations concerning mortality statistics changed several times. The mortality tables were revised six times between 1749 and 1859. A compilation of different versions of Table II is presented in an appendix in Sundbärg (1905), 196-197; Lindahl (1986), $151-153$.

24 Puranen (1984), 64.

25 T. Bengtsson (1988), 467. 
1774, it was replaced by "unspecified disease," a diagnosis that no longer applied only to children. ${ }^{26}$ In Linköping this change in terminology resulted in a shift from high infant mortality caused by unknown childhood diseases to an equally high level of mortality in the category slag. ${ }^{27}$ The remarkable increase in infant mortality caused by slag was illusory, not real. ${ }^{28}$

A change in regulations that affected mortality statistics, on the aggregate as well as the nominal level, was Tabellkommissionens 1831 decision that the clergy would no longer be required to report death statistics, unless the deaths were caused by miscarriage or delivery, by specific accidents or by smallpox. Deaths caused by infectious diseases such as measles, scarlet fever and dysentery were to be reported only if there were extensive epidemics. As a result of this decision, Swedish cause of death statistics are incomplete for the period 1831 to 1860 , and causes of death were not always reported in the death and burial records. ${ }^{29}$ Puranen found, for example, that the share of registered causes decreased in seven different parishes after 1830 . The exception was parishes where the priests had been educated in the "era of pastoral medicine," a period when the ambition was to train clergymen to become physicians and physicians to become clergymen. In spite of the changed regulations the medically educated clergy continued to report causes of death as long as they held office, but when a new parish priest arrived (after 1830) the share of reported causes of death decreased. ${ }^{30}$

This conclusion can be illustrated by an example from Västanfors parish, studied by Tommy Bengtsson. The vicar since 1806, Eric Eggertz, was not affected by the 1830 change in regulations, but rather continued to register causes of death throughout his period of service. According to Bengtsson, his registration actually improved in the 1830s. When Eggertz successor, Georg Seseman took office in 1841, he adopted the new instructions and "about one quarter of the deaths were left without any notice of the causes." 31 In many parishes, however, the clergy continued to register this information. In Linköping, almost all deaths between the

26 Nyström (1986), 129.

27 The Swedish term slag would normally be translated as stroke, but in the case of infant and child deaths slag should be understood as sudden death.

28 Sundin (1996), 97.

29 Lindahl (1986), 136.

30 Puranen (1984), 64.

31 T. Bengtsson (1988), 468. 
years 1831 and 1860 were given a cause of death. ${ }^{32}$ In the town of Sundsvall, the clergy also registered causes of death in the statistical tables after $1830 .^{33}$

As discussed above, the clergy's medical competence and instructions and regulations for mortality statistics influenced the registration of causes of death. Another equally important prerequisite was the individual parish priest's opportunities to collect information about the death. Had the clergyman visited the dying parish member or had he seen this person shortly after death? He may have based his entries on reports given by relatives. ${ }^{34}$ This is difficult to ascertain but is important for the quality of mortality data. Widén argues concerning the clergy that "in their capacity as spiritual guides they may many a time [have] visited those taken seriously ill." 35 However, in the case of infants and children who had suddenly become ill, it is not certain that the parish priest arrived at the sickbed in time. Were there other factors related to the individual clergyman affecting cause of death information? As discussed above, the clergy's medical education and experience varied considerably. Another circumstance is that parish priests could have interpreted the instructions concerning reporting cause of death differently. ${ }^{36}$ In her study of tuberculosis Britt-Inger Puranen found a connection between individual priests and the use of different classifications for chest and lung diseases. While one parish priest used the term consumption, another wrote chest disease for the same complaint. Puranen emphasizes therefore the importance of analyzing cause of death information specific to priests, as well as the use of local terminology for diseases over time. ${ }^{37}$ Tommy Bengtsson is not convinced by Puranen's arguments. An observed under-registration of a certain category of causes of death (in comparison with mortality levels in the office of predecessors and successors) may incorrectly be explained as the effect of individual priests. The variation might, Bengtsson argues,

32 Sundin (1996), 95-96; Hans Nilsson, Mot bättre hälsa. Dödlighet och hälsoarbete i Linköping 1860-1894 (Linköping, 1994), 36.

33 It is not known, however, if the information was registered in the death and burial records, as these were destroyed in the fire of 1888. Sören Edvinsson, Den osunda staden. Sociala skillnader i dödlighet i 1800-talets Sundsvall (Umeå, 1992), 27, 32.

34 Imhof and Lindskog (1973), 140.

35 Widén (1975), 94.

36 Some of the problems associated with cause of death statistics today are the discrepancies between diagnoses made before and after an autopsy and between diagnoses in the autopsy report and on the death certificate. Not all physicians follow the instructions for filling in a death certificate, and some errors also originate when statistics are registered. Lindahl (1986), 135-162.

37 Puranen (1984), 68. 
just as well be explained by real changes in the disease panorama and in changes of the Church Law and the instructions. ${ }^{38}$

Thus far, we have concentrated on the determination and registration of cause of death. Scholars have been rather optimistic in evaluating the clergy's ability to pinpoint cause of death. It was not so much the clergy's medical education as their practical experience. Thanks to their acquaintance with the parish members and their function as spiritual guides, they acquired knowledge on lethal diseases and significant symptoms. On the matter of how instructions and regulations influenced cause of death registration on the parish level, opinions were divided. Several authors emphasized methodological questions regarding Tabellverket's cause of death categories and agreed that the construction of categories is the heart of the matter. Individual factors influencing cause of death registration were also considered important, but difficult for the historian to detect.

When it comes to the researcher's possibility to interpret cause of death data and use the information in order to understand mortality changes over time, some authors are more pessimistic. Tommy Bengtsson argued for instance, that the clergy's ability to recognise deaths from infectious diseases did not facilitate the interpretation of mortality changes, as these diseases not were as frequent: for example, measles, whooping cough and thrush. The most frequently reported causes of death from the eighteenth and nineteenth centuries, such as stroke, unknown child disease and infirmities of old age, were vague and are therefore difficult to interpret. "From the point of view of medical history, these [infectious] diseases are of course as interesting as the more common diseases, but from a social and economic historical point of view they are less important." ${ }^{40}$

Imhof and Lindskog were also rather pessimistic concerning the interpretation of cause of death data. From their medical perspective there are a number of reasons why modern researchers should have difficulties in understanding a number of diseases and causes of death. First, medical terminology and medical science have experienced continuous change in history. Jaundice can serve as an example for a condition that was regarded as a disease in the eighteenth century and is nowadays considered a symptom. Secondly, our modern system of disease is based on pathological and anatomical changes, while eighteenth century physicians took symptoms as their starting-point. ${ }^{41}$ Thirdly, many diseases display a "pure historic variation and change throughout the centuries." Imhof and Lindskog therefore recommended care when translating diagnoses from the eighteenth century to diagnoses

38 T. Bengtsson (1988), 472.

39 T. Bengtsson (1988), 479-481.

40 T. Bengtsson (1988), 480.

41 See also T. Bengtsson (1988), 464. 
of today. In the summary of their article their standpoint is even more pessimistic: "The eighteenth century diagnoses are discussed and found impossible to translate into the medical language of our days." ${ }^{42}$

Jan Sundin has expressed a more optimistic view than Bengtsson, Imhof and Lindskog, saying that "available statistical categories can provide a lot of insight into contemporary concepts of death, disease, and illness...". ${ }^{43}$ A solution to the problem of uncertain and vague cause of death categories is, according to Sundin, to combine cause of death analyses with other indicators for cause of death, for example, seasonal analyses and biometric analyses of mortality. ${ }^{44}$ One possibility, pointed out by Britt-Inger Puranen, is to analyse cause of death information specific to clergymen as well as local terminology over time. ${ }^{45}$ Lars Widén also belongs to the more optimistic researchers: "It is obvious that the data do not meet modern requirements in regard to the reported causes of death. [...] However, it does not mean that these data cannot provide vital information, despite all their shortcomings, on the level and development of mortality during the latter half of the eighteenth century and the beginning of the nineteenth." ${ }^{46}$ There are almost as many opinions concerning the use of historical cause of death data as there are researchers, but it is obvious that the more optimistic authors are those who try to compensate for the short-comings in quality and validity.

\section{A Local Example of Cause of Death Analyses}

Findings from a study on infant and child mortality in Linköping will serve as a starting-point for a discussion of the interpretation of cause of death information and the changes it underwent during the nineteenth century. ${ }^{47}$ Linköping was a rather small town that was dominated by administration, commerce and crafts. By 1800, Linköping had 2,680 inhabitants, and one hundred years later nearly 15,000

42 Imhof and Lindskog (1973), 141-142.

43 Sundin (1996), 93.

44 Sundin (1996), 106. See also Rogers (1999), 209.

45 Puranen (1994), 68.

46 Widén (1975), 93-94.

47 The analyses are based on results from my doctoral dissertation, where three birth cohorts were followed through childhood. Magdalena Bengtsson, Det hotade barnet. Tre generationers spädbarns- och barnadödlighet i 1800-talets Linköping (Linköping, 1996). 
people lived in the city. ${ }^{48}$ During the nineteenth century infant mortality decreased from around 280 to 120 deaths per thousand live births. ${ }^{49}$

The source material consists of computerized parish records, initially registered at the Demographic Data Base at Umeå University. To accentuate the effects of changed regulations for stipulation of causes of death, I have chosen to present the results on infant mortality for two birth cohorts, 1797-1810 and 1870-75, a total of 2,521 individuals. Information on cause of death was given for 96 percent of the infant deaths in the period $1797-1810$ and for 94 percent in the period 1870-1875.

\section{The Early Period, $1797-1810$}

During this period the level of infant mortality was relatively high, with 242.2 deaths per thousand live births, but this was comparable to figures for Sweden for the period, 1811-1820..$^{50}$ The distribution of mortality for different cause of death categories is shown in Table 1.

Slag was the dominant cause of death in the early period and caused over fifty percent of all infant deaths. Slag is an old term for stroke, but here it should be interpreted as sudden death, as I will explain further on. The second most important cause of death was respiratory diseases. Around one fifth of all infant deaths were reported as having been caused by respiratory diseases, and the most common diagnosis was chest fever. ${ }^{51}$ Occasional deaths were caused by chest defects and chest disease. $^{52}$

In the early period, thrush caused nearly ten percent of the infant deaths in Linköping. Thrush (Candida albicans) is an infection in the mouth and throat caused by a yeast fungus. Infant deaths from thrush have been associated with lack of adequate hygiene..$^{53}$ The famous eighteenth century Swedish pediatrician Nils Rosén von Rosenstein was of the opinion that the infants who suffered most from

48 Folke Lindberg, Linköpings historia, del 3. 1567-1862. Sambälls- och kulturliv (Linköping, 1975), 12; Sven Hellström (ed), Linköpings Historia Del 4. Tiden 1863-1910 (Linköping 1978), 13.

49 Lindberg (1975), 15; Parish statistics for Östergötland, Demographic Data Base, Umeå University.

50 Historisk Statistik för Sverige. Del 1 Befolkningen (Örebro, 1955), 60.

51 In the original: bröstfeber.

52 In the original: bröstfel and bröstsjukdom.

53 Ulla-Britt Lithell, Kvinnoarbete och barntillsyn i 1700- och 1800-talets Österbotten (Stockholm, 1988), 14. 
Table 1. Mortality distribution for different causes of death during infancy. Linköping, 1797-1810 and 1870-1875.

\begin{tabular}{lcrrr}
\hline & $\mathbf{1 7 9 7 - 1 8 1 0}$ & \multicolumn{3}{c}{$\mathbf{1 8 7 0 - 1 8 7 5}$} \\
\hline Number of live births & 1251 & & 1270 & \\
Cause of death & IMR & $\mathbf{n}$ & IMR & $\mathbf{n}$ \\
Atrophy & 0.8 & 1 & 14.9 & 19 \\
Childhood diseases & 20.0 & 25 & 18.1 & 23 \\
Congenital diseases & & 0 & 32.3 & 41 \\
Gastro-intestinal infections & & 0 & 62.2 & 79 \\
Other diseases & 1.6 & 2 & 11.0 & 14 \\
Respiratory diseases & 49.6 & 62 & 29.9 & 38 \\
Slag & 134.3 & 168 & 3.9 & 5 \\
Thrush & 22.4 & 28 & 0.8 & 1 \\
Tuberculosis & & 0 & 2.4 & 3 \\
Unknown, illegible or unspecified & 13.6 & 17 & 10.2 & 13 \\
\hline Total & 242.2 & 303 & 172.4 & 219 \\
\hline
\end{tabular}

Source: DDB, Umeå University.

thrush were those whose mouths were not properly cleaned and those who sucked old, thick or sour milk. ${ }^{54}$

Smallpox was the most important childhood disease at this time and caused around five percent of all deaths, or 12.8 deaths per thousand. In Linköping, vaccination against smallpox began as early as 1802, which was fourteen years before vaccination became compulsory in Sweden. The town medical officer, Olof Noraeus, performed about 4,000 vaccinations in two years. ${ }^{55}$ Other diagnoses in this category were whooping cough and measles. A small epidemic of whooping cough took place in this area between June and November 1806. Finally, there were two small categories, undefined fevers and atrophy. Atrophy contained diagnoses such as consumption and wasting disease. ${ }^{56}$

A quick look at cause of death patterns in different age spans during the first year reveals that slag was the most common cause of death in the first month after birth (Tables 2-4). At ages 2-6 months, deaths from respiratory diseases had become more common, but slag was still a dominant cause of death. Deaths from childhood diseases became more common in the second half of the first year, whereas thrush had almost disappeared.

54 Nils Rosén von Rosenstein, Underrättelse om barns sjukdomar och deras bote-medel (Stockholm, 1771), 42.

55 Lindberg (1975), 41.

56 In the original: tvinsot and tärande. 
Table 2. Mortality distribution for different causes of death, ages 0-30 days. Linköping, 1797-1810 and 1870-1875.

\begin{tabular}{lcccr}
\hline & $\mathbf{1 7 9 7 - 1 8 1 0}$ & & $\mathbf{1 8 7 0 - 1 8 7 5}$ & \\
\hline Number of live births & 1251 & & 1270 & \\
Cause of death & IMR & $\mathbf{n}$ & IMR & $\mathbf{n}$ \\
Childhood diseases & - & 0 & 1.6 & 2 \\
Congenital defects & - & 0 & 19.7 & 25 \\
Gastro-intestinal infections & - & 0 & 14.2 & 18 \\
Respiratory diseases & 2.4 & 3 & 6.3 & 8 \\
Slag & 37.6 & 47 & 1.6 & 2 \\
Thrush & 10.4 & 13 & 0.8 & 1 \\
\hline Total & 61.6 & 77 & 54.3 & 69 \\
\hline
\end{tabular}

Source: DDB, Umeå University.

Table 3. Mortality distribution for different causes of death, ages 2-6 months. Linköping, 1797-1810 and 1870-75.

\begin{tabular}{lcrrr}
\hline & $\mathbf{1 7 9 7 - 1 8 1 0}$ & \multicolumn{1}{c}{$\mathbf{1 8 7 0 - 1 8 7 5}$} \\
\hline Number of live births & 1251 & & 1270 & \\
Cause of death & IMR & $\mathbf{n}$ & IMR & $\mathbf{n}$ \\
Childhood diseases & 7.2 & 9 & 5.5 & 7 \\
Congenital defects & - & 0 & 7.1 & 9 \\
Gastro-intestinal infections & - & 0 & 29.1 & 37 \\
Respiratory diseases & 25.6 & 32 & 19.7 & 25 \\
Slag & 74.3 & 93 & 0.8 & 1 \\
Thrush & 9.6 & 12 & - & 0 \\
\hline Total & 115.1 & 144 & 67.7 & 86 \\
\hline
\end{tabular}

Source: DDB, Umeå University.

Table 4. Mortality distribution for different causes of death, ages 7-12 months. Linköping, 1797-1810 and 1870-1875.

\begin{tabular}{lcrrr}
\hline & $\mathbf{1 7 9 7 - 1 8 1 0}$ & \multicolumn{3}{c}{$\mathbf{1 8 7 0 - 1 8 7 5}$} \\
\hline Number of live births & 1251 & & 1270 & $\mathbf{n}$ \\
Cause of death & IMR & $\mathbf{n}$ & IMR & $\mathbf{n}$ \\
Childhood diseases & 14.4 & 18 & 11.0 & 14 \\
Congenital defects & - & 0 & 3.1 & 4 \\
Gastro-intestinal infections & - & 0 & 18.1 & 23 \\
Respiratory diseases & 21.6 & 27 & 12.6 & 16 \\
Slag & 22.4 & 28 & 1.6 & 2 \\
Thrush & 2.4 & 3 & - & 0 \\
\hline Total & 60.0 & 75 & 49.6 & 63 \\
\hline
\end{tabular}

Source: DDB, Umeå University. 


\section{The Late Period, $1870-1875$}

The most important change in the period 1870-1875, when compared to the earlier period, was that slag had more or less disappeared as a cause of death (see Table 1). Instead, gastro-intestinal diseases had taken its place as the dominant cause of death, and responsible for 36 percent of all infant deaths.

Respiratory disease was still the second largest cause of death category and was reported to have caused 17 percent of the infant deaths. This category had also been enlarged by the addition of new diagnoses: chest catarrh, bronchial inflammation, lung catarrh and pneumonia. ${ }^{57}$

Childhood diseases were reported as the cause of ten percent of all infant deaths during the late period. Smallpox, measles and whooping cough had appeared as causes of death in the earlier period, but scarlet fever and diphtheria were relatively new diagnoses. Smallpox caused the largest number of deaths in this category, and 17 out of 23 deaths were given this diagnosis. Mortality from smallpox had gradually decreased in the decades following the introduction of vaccination, ${ }^{58}$ but mortality increased when serious epidemics struck the city in 1863 and 1874-1875. ${ }^{59}$

Several causes of deaths can be categorized as congenital defects: prematurity, convulsions, congenital syphilis, deformities and weakness. These diagnoses are probably related more to conditions in the uterus and circumstances at birth and are less likely to be associated with exogenous factors.

The analyses of cause of death patterns in different age spans during the first year show that congenital defects together with gastro-intestinal diseases dominated mortality in the first month after birth (Tables 2-4). Mortality from respiratory infections became more prominent at the age of 2 to 6 months, even though gastrointestinal diseases were still responsible for the highest mortality in that age group. During the second half of the first year mortality was more evenly distributed among the categories gastro-intestinal diseases, respiratory infections and childhood diseases.

\section{Discussion}

How should the information on cause of death given in the death and burial records be interpreted in this case? And how should the changes in cause of death patterns described above be understood?

57 In the original: bröstkatarr, luftrörsinflammation, lungkatarr and lunginflammation.

58 Sundin (1996), 97.

59 Nilsson (1994), 115-117. 
Let me begin with the cause of death category slag. In the early period, infant mortality from slag was extremely high in Linköping, at the same time as no deaths from gastro-intestinal diseases were reported. This relationship was reversed in the later period, when physicians were required to issue death certificates. The fact that not a single infant born in Linköping between 1797 and 1810 died from a gastrointestinal infection should not be interpreted to mean that the infants did not suffer from diarrhea.

We know from studies in the developing countries of today that diarrhea is one of the major causes of death among children. It is estimated that about one tenth of the children die from gastro-intestinal infections before five years of age. ${ }^{60}$ Although conditions in seventeenth and eighteenth century Europe are not completely comparable with the situation in the developing countries of today, the chances these infants have for survival are believed to be similar, due to similar hygienic conditions in both environments. It is therefore likely that similarities can be found in the cause of death patterns. There is also evidence from historical studies of Swedish and Finnish parishes that gastro-intestinal diseases have been reported as the cause of death for infants. ${ }^{61}$ In Tanum, a coastal parish in southwestern Sweden, a third of the deceased infants who had been given a cause of death between 1780 and 1800 had died from gastro-intestinal diseases. ${ }^{62}$ Accordingly, there seem to have been local variations in the practice of using diarrhea and slag as the cause of death for infants.

I am inclined to think that at the beginning of the nineteenth century, infant deaths in Linköping that were caused by diarrhea were registered as another cause of death, such as slag, for example. That does not mean, however, that diarrhea was the cause of all infant deaths attributed to slag! There are a number of interpretations of the underlying cause of infant deaths noted in this category. In a study of cause of death patterns in Västanfors from 1700 to 1925, Tommy Bengtsson argued that slag contained all causes leading to sudden death. ${ }^{63}$ It could naturally be argued that all infant deaths that could not be diagnosed as smallpox, measles, whooping cough, thrush or respiratory infections were given the diagnosis slag.

How did a contemporary physician reason about infant deaths caused by slag? The famous eighteenth century Swedish physician Nils Rosén von Rosenstein discussed convulsions and heart irregularity (hjärtspraing) in the third and enlarged

60 S. Martin Taylor et al., "Modelling the incidence of childhood diarrhea," Social Science of Medicine, 23:10 (1986), 995.

61 Brändström (1984); Ulla-Britt Lithell, Breast-Feeding and Reproduction. Studies in Marital Fertility and Infant Mortality in 19th century Finland and Sweden (Stockholm, 1981).

62 Brändström (1984), 199.

63 T. Bengtsson (1988), 481. 
edition of his pediatric volume. ${ }^{64}$ He believed that infants reported as dying from slag had in reality suffered from heart irregularity:

When one of their limbs twitches, we say that they have convulsions, but when the whole body twitches, and they are also blue in the face, we say that they suffer from heart irregularity ... A paroxysm of heart irregularity consists of two parts. The first is the twitches, and the other is the consequences, namely a deep sleep with a murmuring sound in the chest. It is during this [sleep], that they die, and since they are then lying there like one who is struck with slag, it is said that these children die from slag, which is in truth the case. Therefore we read in the weekly papers that so many infants are declared to have died from slag, although the real cause was heart irregularity. ${ }^{65}$

The convulsions mentioned above could possibly be interpreted as symptoms of dehydration. Diarrhea may cause dehydration, which can lead to a life-threatening condition in a very short time. Today these children are given intravenous fluids and are sometimes treated in hospital. ${ }^{66}$ Another possible explanation for the convulsions is a tetanus infection. Tetanus, caused by an infection at birth or via the navel as a result of inadequate hygienic measures, is a relatively common cause of death among infants in developing countries. It is a serious condition, as only half of the infected infants survive. ${ }^{67}$

Some of the infant deaths caused by slag may, of course, have been what today is called sudden infant death syndrome, SIDS, a term for infant deaths where the cause of death cannot be explained by clinical circumstances, the situation at the time of death, or the autopsy. The reason some infants die suddenly, without any apparent cause, has not been completely elucidated, but several studies have shown that mortality was reduced when it was recommended that parents place babies on their backs rather than on their stomachs for sleep. ${ }^{68}$

Several excerpts from Rosén von Rosenstein's book give advice on how to position the infant in bed:

64 Rosén von Rosenstein (1771).

65 Rosén von Rosenstein (1771), 46-48. Author's translation.

66 Taylor, et al. (1986), 995.

67 Melvin I. Marks, Pediatric Infectious Diseases for the Practitioner (New York, 1985), 636.

68 Torleiv Ole Rognum, ed. Sudden Infant Death Syndrome - New Trends in the Nineties (1995). 
She [the wet-nurse] should never hold an infant straight up and down unless its head is supported by something. Likewise, an infant should always lie with its head a little higher than its body or it is prone to die of slag.

This reference to the importance of the position of the head suggests a similarity between slag and sudden infant death syndrome. It is difficult to trace any sign of sudden infant death syndrome in the death and burial records from Linköping during the nineteenth century, but successful attempts have been made in other parts of Sweden. ${ }^{69}$

To sum up this discussion so far, there is strong evidence for an interpretation of slag as equivalent to diarrhoea. First, the diagnosis changed from slag to diarrhoea when death certificates issued by physicians were required, starting in 1860. Secondly, there is some similarity with developing countries of today in cause of death patterns, and thirdly, there is evidence from other historical studies. The transformation from slag to gastro-intestinal diseases may have been due to changes in practice (exemplified by local variations in the use of diarrhoea as the cause of death), and to the regulation about death certificates. An important effect of the regulation of 1860 is that medical expertise, together with the midwife, became responsible for establishing the cause of infant deaths in the cities, something that consequently should have made the information on cause of death more accurate than before.

This shift in medical competence is also apparent with respect to the cause of death category congenital defects. At the beginning of the nineteenth century not a single death was reported among infants in Linköping as being caused by a congenital defect. By the mid-nineteenth century, the picture had changed somewhat: of the total of 225 infants who died during the period 1840-1849, approximately thirteen percent were given the diagnosis weakness. Two cases of hydrocephalus and one case of congenital syphilis were also reported. It is likely that a physician had examined the infants suffering from these latter two conditions, as they were of particular medical interest. For the infants dying of weakness, the clergyman probably established the cause of death himself after having talked with the parents.

In the period 1870-1875, two new diagnoses were added to the category congenital defects, namely prematurity and convulsions. Nearly one fifth of all infant deaths at this time were categorised as congenital defects, and the dominant diagnosis was weakness (13.4 deaths per thousand). Thereafter followed deformities (7.1 deaths per thousand) and prematurity (5.5 deaths per thousand).

The variety of deformities tells us something about the careful attempts of physicians to find the accurate cause of death: too much blood to the lungs, incomplete

69 Bodil E. B. Persson, "Barnkvävning och plötslig spädbarnsdöd (=SIDS)," Scandia, 62:2 (1996) 195-219. 
lung development, dissociated spine and lung collapse. ${ }^{70}$ Of course, the change in terminology reflects not only the entrance of the physician into the picture but also increased medical knowledge as well. Some causes of death in this category were not really causes, but were actually symptoms of disease, e.g. weakness and convulsions, but the various examples of deformities and the term prematurity are all examples of a cause of death terminology aimed at explaining what really caused the deaths.

Consequently, this shift can be characterized as the development from symptombased to cause-based terminology. Symptoms are easier to recognize for a lay person, such as the clergyman, but extensive medical knowledge is required for the identification of causes. It is likely that that the increased accuracy of the diagnoses over time can be explained, not only by the physician's entrance onto the stage, but also by the scientific developments within medicine during the nineteenth century.

In fact, the first systematic descriptions and classifications of disease were based on symptoms. The French botanist and medical professor François Boissier de la Croix de Sauvage (1706-1767) selected symptoms as the primary criteria for classifications of disease. De Sauvage dismissed causes of disease as criteria for classification, as all assumptions of causality were only vague suppositions. Carl von Linné (1707-1778) also developed a nosology based on symptoms, in which 11 classes were grouped as fevers or non-fevers. The non-fevers were divided into diseases of the nervous system, the body fluids and the firm parts of the body. ${ }^{71}$ The Scottish physician William Cullen (1710-1790) developed a new classification scheme based on his own experience as naval surgeon, private physician and university professor in charge of hospital patients. According to the medical historian Guenter B. Risse, "Cullen criticized his predecessors for attempting comprehensive arrangements not entirely based on personal observations, because lack of firsthand knowledge made them include virtually every symptom as a separate disease". ${ }^{72}$ Although the system developed by Cullen was to a large degree also based on symptoms, he formulated the principle of physiological function as a criterion for the classification of nervous disorders. As important medical discoveries continued to take place in the nineteenth century, it became more and more obvious that the old nosology systems were of no use. The new medical disciplines of anatomy, physiology and cell biology demanded totally new categories, and it was not until 1893 that a classifica-

70 In the original: blodträngsel till lungorna, ofullständig lungutveckling, kluven ryggrad, and lungkollaps.

71 Lennart Nordenfelt and Eva Nyström "Sjukdomsklassifikation i historisk belysning," in Hälsa, sjukdom, dödsorsak. Studier i begreppens teori och historia, ed. L. Nordenfelt (Linköping, 1986), 82-85.

72 Guenter B. Risse, Hospital Life in Enlightenment Scotland. Care and Teaching at the Royal Infirmary of Edinburgh (Cambridge, 1986), 116. 
tion system founded on anatomy and topology was presented. Jaques Bertillon declared that diseases should be classified according to what part in the body had been affected. ${ }^{73}$

A change in the cause of death pattern that was independent of regulations, practice or the state of medicine is exemplified by developments regarding mortality from diphtheria and scarlet fever in the nineteenth century. These infectious diseases were not reported as causes of death in Linköping in the beginning of the nineteenth century, but appeared in the period 1870-1875. In fact, diphtheria and scarlet fever appeared as new pandemics during the second half of the nineteenth century. ${ }^{74}$ During the 1860 s and 1870 s mortality from diphtheria and scarlet fever was very high in Sweden and these diseases had increased in importance regarding child mortality. ${ }^{75}$ Three major epidemics of scarlet fever struck Linköping in the latter part of the $19^{\text {th }}$ century, namely in $1856-1857,1877-1878$ and $1892-1894$. The majority of the deceased were children under six years of age. ${ }^{76}$ In Sundsvall, there were large increases in mortality in children aged 1-4 years that were mainly due to epidemics of scarlet fever and diphtheria. ${ }^{77}$ Consequently, a change in the epidemiological pattern not only influenced conditions in Linköping, but in all of Sweden. ${ }^{78}$ The changes in mortality due to diphtheria and scarlet fever should thus be interpreted as a shift in the epidemiological regime.

73 Nordenfelt and Nyström (1986), 85-87, 96-97.

74 Alex Mercer, Disease, Mortality and Population in Transition. EpidemiologicalDemographic Change in England since the Eighteenth Century as part of a Global Phenomenon (Leicester, 1990), 115, fig 5.5.

75 Rolf Bergman, "De epidemiska sjukdomarna och deras bekämpande," in Medicinalväsendet i Sverige 1813-1962, ed. W. Kock (Stockholm, 1963), 334; Erland Hofsten and Hans Lundström, Swedish Population History. Main Trends from 1750-1970 (Stockholm, 1976), 59; Marie C. Nelson, "Diphtheria in late-nineteenth-century Sweden: policy and practice," Continuity and Change, 9:2 (1994), 222.

76 Annika Bergström, Dödlighet i scharlakansfeber i Linköping på 1800-talet, unpublished paper, Dept. of History (Linköping, 1995)

77 Edvinsson (1992), 181.

78 Marie C. Nelson and John Rogers, "The Epidemiological Transition in Sweden. Some Regional Implications," paper presented at The 18th annual meeting of Social Science of History Association (New Orleans, 1993). 


\section{Final Comments}

Is it possible to use information on cause of death from the eighteenth and nineteenth centuries in mortality analyses? How should we interpret and use causes of death in mortality analyses?

It has been argued that the clergy, who were responsible for designating cause of death up until 1830, had insufficient medical knowledge and that the information is therefore unreliable. It has also been argued that the science of medicine was rather underdeveloped during the eighteenth and nineteenth centuries, and death certificates issued by physicians were therefore not always reliable. While I agree that it can be difficult to use cause of death information for the purpose of identifying factors influencing infant and child mortality and explaining changes in mortality, to simply ignore this kind of information does not seem wise. The question is how it may be used.

Results from a study on infant mortality in Linköping have served as a startingpoint for this discussion. In addition, different reasons for changes in cause of death patterns have been analyzed. The diagnosis slag was reported as having caused more than half of all infant deaths in the early nineteenth century, and I have pointed out several reasons why slag, in this particular context, should be interpreted primarily as diarrhea. Analyses of cause of death patterns revealed different types of change. Changes in practice, regulations and medical science are exemplified in the transformation of slag and congenital defects, whereas the appearance of diphtheria and scarlet fever in the mortality pattern was related to variations in the epidemiological regime.

In performing local studies where cause of death information is placed in its proper context, and analyses are combined with other kinds of mortality analyses, I believe that cause of death analyses are quite useful for understanding mortality and its changes. An awareness of 1) the conditions under which causes of death were rendered, 2) what regulations were in effect at the particular time, and 3) the environmental and epidemiological changes provides good prerequisites for successful use of cause of death information.

Magdalena Bengtsson is Assistant Professor at the Department of Health and Society, Linköping University, SE-501 85 Linköping, Sweden. 


\section{Acknowledgements}

I am grateful to Associate Professor Sören Edvinsson (Umeå University) and Professor Marie C. Nelson (Linköping University) for their helpful suggestions. I also would like to thank Jane Wigertz for reviewing my English. 